\title{
Figuratividade: o complexo elo entre as palavras e as coisas
}

\author{
Figurativity: the complex link between words and things
}

\section{Ada Lima Ferreira de Sousa Marcos Antonio Costa}

Universidade Federal do Rio Grande do Norte - UFRN - Caicó - Rio Grande do Norte - Brasil

\begin{abstract}
Resumo: Este artigo trata do conceito de figuratividade no âmbito dos estudos cognitivos da linguagem. Apresenta a polarização, herdada dos gregos antigos, entre o que se convencionou como figurativo e literal, resultando no entendimento de que pensamento e linguagem são inerentemente literais. Nessa concepção, o figurativo seria um recurso não natural, propositadamente utilizado como estratégia estilística. Assim, o uso da figuratividade passou a ser associado a prejuízos à suposta transparência da linguagem e dos significados a ela inerentes. Embora essa concepção não tenha sido suplantada, as perspectivas cognitivas contemporâneas que tratam do fenômeno linguístico como sendo intrínseco à cognição oferecem-nos uma outra visão acerca da figuratividade. A Teoria Neural da Linguagem, em particular, tem reforçado, teórica e empiricamente, a compreensão acerca dos mecanismos cognitivos envolvidos na construção de sentidos. De igual relevância, esse arcabouço teórico tem apresentado evidências de que as experiências corpóreas estão na raiz da construção de parte das estruturas mentais evidenciadas no uso da linguagem, de modo que a natureza peculiar de nosso corpo contribui para as peculiaridades de nosso sistema conceptual. A integração entre corpo e mente, de modo que emoções e abstrações devam ser conceptualizadas a partir de elementos mais concretos, de base corpórea, oferece novos contornos à explicação para o fenômeno linguístico da figuratividade.
\end{abstract}

Palavras-chave: Figuratividade. Cognição. Teoria Neural da Linguagem.

Abstract: This article deals with the concept of figurativity within the cognitive studies of language. It presents the polarization, inherited from the ancient Greeks, between what is conventionalized as figurative and as literal, which resulted in the understanding that thought and language are inherently literal. In this conception, figurativity would be an unnatural feature intentionally used as a stylistic strategy. Thus, the use of figurativity became associated with damages to the supposed transparency of language and the meanings inherent to it. Although this view has not been supplanted, contemporary cognitive perspectives that treat the linguistic phenomenon as intrinsic to cognition offer us another view on figurativity. In particular, the Neural Theory of Language has both theoretically and empirically reinforced the understanding of the cognitive mechanisms involved in the construction of meaning. Equally important, this theoretical framework has presented evidence that body experiences are at the basis of the construction of mental structures evidenced in the use of language, so that the peculiar nature of our body contributes to the peculiarities of our conceptual system. The integration between body and mind, so that emotions and abstractions must be conceptualized from more concrete body-based elements, offers new dimensions to the explanation for the linguistic phenomenon of figurativity.

Keywords: Methodology. Interpretive research. Dialogism. Group Think-Aloud. 


\section{Introdução}

As construções metafóricas vêm sendo discutidas no âmbito da figuratividade desde a época dos gregos antigos, quando eram vistas necessariamente como tropos linguísticos. Hoje, diversas vertentes do campo da Linguística consideram que elas devem ser tomadas não como recursos retóricos, mas, principalmente, como fenômenos que revelam importantes aspectos das nossas práticas linguísticas cotidianas e da maneira como percebemos o mundo. Esse entendimento está presente, por exemplo, no campo dos estudos cognitivistas, segundo os quais a linguagem não deve ser concebida, em si mesma, como geradora e portadora de sentidos, uma vez que muitos de nossos processos linguísticos, inextricavelmente relacionados ao resto de nosso sistema físico e cognitivo, são figurativamente estruturados.

O interesse pelo fenômeno linguístico da figuratividade pode ser constatado a partir de diversas tradições, assumindo diferentes perspectivas conforme a concepção de linguagem norteadora de cada arcabouço conceptual. De acordo com Gibbs (1994), os méritos do pensamento e da linguagem figurativos têm sido ferozmente debatidos desde 0 tempo dos gregos antigos. À época, Platão defendeu a existência de manifestações linguísticas de naturezas distintas: uma era fantasiosa e expressa na poesia; a outra materializava-se na forma de assertivas que expressavam a realidade constatável pelo homem. Estabelecia-se, nesse momento, a distinção entre o que se convencionou, nas tradições de áreas humanísticas, como figurativo e como literal, respectivamente. Essa polarização herdada dos gregos antigos, que resultou na concepção de figuratividade como uma distorção das verdades do mundo, está na raiz do entendimento de que pensamento e linguagem são inerentemente literais, posto que o figurativo seria um recurso não natural, propositadamente utilizado por poetas e por políticos, por exemplo, para o embelezamento dos textos por eles produzidos. Com isso, ainda conforme Gibbs (1994), o uso da figuratividade, conquanto fosse considerado fruto de uma cognição privilegiada, foi associado a prejuízos à suposta transparência da linguagem e dos significados a ela inerentes.

Embora essa concepção de figuratividade não tenha sido suplantada - uma vez que frequentemente ainda encontramos, por parte de muitos estudiosos, uma explícita desconfiança quanto às limitações da linguagem e do pensamento figurativos -, o fato é que ela coexiste com pelo menos mais uma, detectada no interior de algumas abordagens cognitivas da linguagem que buscam investigar os mecanismos mentais envolvidos nos processos de construção de sentidos, partindo da premissa básica de que a cognição humana é, fundamentalmente, construída por meio da relação do ser humano com o mundo através de experiências sensoriais e motoras e, também, das vivências de cunho social e cultural. Em meados dos anos 1970, pesquisadores ligados a essa vertente buscaram construir modelos teóricos e analíticos em que ficasse evidente a base corpórea da cognição humana. No final dos anos 1980, em decorrência da aproximação de linguistas da cognição com as Ciências da Computação, as Neurociências e a Psicologia Cognitiva, resultados de experimentos científicos permitiram evidenciar 0 comportamento dos circuitos neurais em atividades que envolviam o processamento da linguagem. Esses dados fortaleceram várias premissas básicas desse campo, entre elas a de que não há separação entre mente e corpo, posto que o aparato mental humano se compõe de estruturas que, em sendo construídas a partir da interação física e social do homem com o ambiente em que se encontra, são ativadas em quaisquer atividades que envolvam a necessidade de gerenciar os elementos envolvidos nos processos de construção de sentidos de forma a garantir a semantização dessa experiência interativa. No rastro desse entendimento, está a compreensão de que a linguagem não é uma habilidade desvinculada do aparato cognitivo humano, tampouco um módulo mental isolado em um ponto específico da arquitetura cerebral e responsável por gerar, em si e por si, sentidos para o que percebemos em nossa interação com o mundo. Muito diferentemente, a atividade 
linguística é compreendida como ocorrendo no espaço constituído por indivíduos que criam e compartilham crenças e experiências e que, nessa interação, se conhecem, se apresentam e se ajustam às mais diversas situações.

Norteados por essa perspectiva cognitiva da linguagem, podemos compreender, portanto, que a figuratividade é um fenômeno linguístico intrínseco à cognição humana e fundamental para a arquitetura das nossas relações com o mundo. Ao examinarem o funcionamento da metáfora na linguagem cotidiana, Lakoff e Johnson (2003) concluíram que o pensamento e a linguagem do ser humano são natural e frequentemente estruturados por elementos figurativos. Trata-se de um trabalho pioneiro no âmbito dessa investigação que foi seguido por tantos outros igualmente de grande relevância para a desconstrução do entendimento de que os elementos figurativos são, via de regra, conscientemente escolhidos para fins de embelezamento da linguagem. Pesquisas realizadas no âmbito da Teoria Neural da Linguagem, desenvolvida a partir de 1988 por Jerome Feldman e George Lakoff, reforçam a compreensão acerca dos mecanismos cognitivos envolvidos na construção de sentidos. Em Lakoff e Johnson (1999), a inserção da perspectiva corporificada no campo do cognitivismo se consolida, corroborando a visão, surgida na segunda metade do século $X X$, de que a linguagem não é mera expressão dos pensamentos ou instrumento de representação do real. Para os autores, as experiências corpóreas estão na raiz da construção de parte das estruturas mentais evidenciadas no uso da linguagem, de modo que as peculiaridades do corpo humano - por exemplo, o modo como nosso sistema visual funciona a serviço da conceptualização do espaço, ou a maneira como gerenciamos nossos movimentos, dentre outras tantas atividades de interação com o ambiente em que nos encontramos - contribuem para as peculiaridades de nosso sistema conceptual. Essa visão é reforçada por Gibbs (2005), que define cognição como o processo de engajamento do corpo em um mundo físico e cultural. Em decorrência disso, o pensamento é a própria ação do homem no ambiente com o qual interage. Assim, pode-se conceber a mente como sendo o próprio corpo, afinal, sem ele não há pensamento nem linguagem.

Esses são apenas alguns nomes, ao lado de muitos outros, que nos permitem traçar, ainda que de forma breve, uma trajetória histórica que contemple as últimas décadas dos estudos voltados para a interface linguagem-cognição e que muito nos têm a dizer acerca do que rotulamos por figuratividade. No próximo tópico, procuramos desenhar essa trajetória.

\section{Cognição e Estudos da Linguagem}

O primeiro passo para o estabelecimento do cognitivismo no interior dos estudos da linguagem foi dado na Conferência sobre Inteligência Artificial de Dartmouth, nos Estados Unidos, em 1956. Na ocasião, especialistas da área se reuniram durante seis semanas com o objetivo de compreender os processos mentais com base em um modelo computacional. Durante o evento, Noam Chomsky, professor de Linguística do Instituto de Tecnologia de Massachussets, argumentou a favor da existência de propriedades formais na linguagem humana. Apenas um ano depois, Chomsky publicou o livro Syntactic Structures, considerado o marco do Gerativismo. Segundo Kenedy (2008), essa vertente surgiu como uma espécie de resposta ao Behaviorismo, corrente que dominou as ciências em geral durante a primeira metade do século $X X$ e, no contexto dos estudos da linguagem, torna-se a base epistemológica para a ideia de que a linguagem é um sistema de hábitos resultantes de respostas recorrentes do organismo aos estímulos sociais. Assim, na perspectiva behaviorista, a mente do bebê é uma tábula rasa; à medida que a criança vai interagindo com o meio, ela desenvolve conhecimentos linguísticos decorrentes da imitação e, também, de "recompensas" em troca do desempenho satisfatório. Chomsky confrontou a proposta behaviorista ao afirmar que todos os falantes nascem com uma capacidade interna ao cérebro humano, chamada faculdade da linguagem, e que é ela que nos permite adquirir uma língua. Essa faculdade inata, de acordo com Chomsky, distinguiria 
o ser humano dos outros primatas superiores e das demais espécies animais. Assim, com o surgimento do Gerativismo, a linguagem humana passou a ser vista não como um comportamento socialmente condicionado, mas um dispositivo mental inato. Nessa perspectiva, considera-se que os falantes são dotados de uma "língua interna" constituída por um número finito de regras, e que, a partir dessas regras, eles conseguem entender e criar um número infinito de frases, inclusive as nunca antes formuladas ou ouvidas. Essa capacidade é denominada pelos gerativistas de criatividade. Em decorrência dessa concepção, as investigações empreendidas acerca da linguagem se limitariam aos fatores internos, de caráter individual, e disso resulta a escolha, pelos gerativistas, de não priorizar os aspectos extralinguísticos em suas análises. Nesses termos, observar o funcionamento da linguagem correspondia a verificar a competência linguística do falante, ou seja, seu conhecimento inconsciente acerca da língua. Questões referentes ao desempenho linguístico, ou seja, ao uso concreto da língua, deveriam ser descartadas, posto que problemas de execução (a exemplo dos erros de pronúncia) estão, comumente, relacionados a fatores não linguísticos (conhecimento de mundo, desequilíbrio emocional, nível de atenção) e não indicam, necessariamente, comprometimento da competência. Estabelece-se, assim, uma dicotomia entre competência e desempenho, que indica um posicionamento cartesiano da parte de Chomsky e abre espaço para inferir que o gerativismo não admite uma relação direta entre os processos mentais e os da ordem do uso.

O confronto a essa perspectiva iniciou-se ainda na segunda metade do século XX por iniciativa de alguns linguistas, como, por exemplo George Lakoff, Háj Ross, James McCawley e Paul Postal. Esses autores, impulsionados pelo interesse na investigação do fenômeno da significação (já iniciado, inclusive, no interior da própria tradição gerativista pelo movimento da Semântica Gerativa) e também pela investigação psicolinguística de Eleanor Rosch (ROSCH, 1978; ROSCH; MERVIS, 1975) sobre o papel fundamental dos protótipos no processo de categorização, encabeçam a formação de uma nova geração cognitivista que vai se voltar para uma abordagem da linguagem perspectivada como meio de conhecimento e em conexão com a experiência humana do/no mundo. Desse modo, abandona-se a tese da autonomia de uma "faculdade da linguagem", e as estruturas linguísticas passam a ser estudadas como resultantes de processos que lhes são subjacentes e que estão intimamente relacionados às capacidades cognitivas gerais, à organização conceptual, aos princípios de categorização e à experiência cutural, social e individual. Concomitantemente à construção desse novo paradigma, a dicotomia mente/corpo, herança cartesiana, dá lugar a uma abordagem que valoriza o papel do corpo humano na construção do aparato cognitivo e, consequentemente, nas práticas relacionadas à linguagem.

Vale ressaltar ainda que, considerando a fundamentação teórica e conceptual desse novo paradigma cognitivo nos estudos linguísticos, temos que os processos de significação se tornam 0 fenômeno linguístico primário a ser investigado e, consequentemente, a categorização se configura como função primária da linguagem. E é exatamente por conta de sua função categorizadora que a linguagem deixa de ser compreendida como "representação", seja do mundo ou do pensamento, como ditam as visões tradicionais, e passa a ser compreendida como um instrumento que nos permite forjar a própria arquitetura do mundo, simultaneamente interpretando-o e construindo-o.

\subsection{A Metáfora como um Fenômeno de Base Cognitiva}

Os estudos sobre a metáfora têm como berço a Filosofia Clássica. Por volta do século IV a.C., Aristóteles (s.d., p.33), em seus escritos sobre arte e poesia, cunhou a seguinte definição: "a metáfora é a transposição do nome de uma coisa para outra, transposição do gênero para a espécie, ou da espécie para o gênero, ou de uma espécie para outra, por 
analogia". De acordo com Gibbs (1994), da definição de Aristóteles vêm duas ideias importantes. A primeira é a de que a metáfora tem a ver com os sentidos das palavras, posto que é no nível delas, não das sentenças, que ocorre a transferência metafórica; a segunda é a de que a metáfora é um desvio do uso literal da linguagem, pois envolve a transferência, para um objeto, de um nome que não pertence, propriamente, a ele.

Percebe-se, na raiz dessa concepção, a ideia de que os significados pertencem às palavras e que qualquer operação que implique em modificar essa ordem de coisas é tida como desvio. No caso da metáfora, ainda de acordo com Aristóteles (s.d., p. 35), trata-se de um desvio com a função de tropo linguístico, o que se sustenta na afirmação: "a elocução mantém-se nobre e evita a vulgaridade, usando vocábulos peregrinos (chamo peregrinos os termos dialetais), a metáfora, os alongamentos, em suma tudo o que se afasta da linguagem corrente". Daqui também se infere a concepção da metáfora como recurso escolhido a dedo, com fins de ornamentação, não associado a práticas cotidianas.

Embora a concepção clássica tenha se firmado a ponto de ainda ser frequentemente evocada quando se trata de figuratividade de um modo geral, a reação a ela vem se desenhando desde o final dos anos 1970. Em 1979, Reddy redigiu um ensaio denominado The conduit metaphor, em tradução livre, A metáfora do canal. Nele, o autor faz um estudo metalinguístico acerca da comunicação com base na análise da fala de informantes da língua inglesa. Reddy percebeu que frequentemente utilizamos metáforas em referência ao próprio ato de nos comunicarmos uns com os outros. Isso fica evidente em sentenças como você ainda não me deu nenhuma ideia do que queira dizer e você deve colocar cada conceito em palavras com muito cuidado, nas quais os significados são coisas enviadas pelo falante para a mente do receptor, através das palavras, que seriam o tal "canal" mencionado no título do ensaio.

O trabalho de Reddy foi apenas um dos produzidos no final dos anos 1970 que confrontavam a concepção tradicional de metáfora. Nesse mesmo período, Lakoff e Johnson escreveram o livro Metaphors we live by, lançado em 1980 e considerado a obra fundante da concepção de metáfora que viria a ser adotada, total ou parcialmente, por grande parte dos pesquisadores vinculados ao campo dos estudos cognitivos da linguagem. Nesse trabalho, Lakoff e Johnson propõem a Teoria da Metáfora Conceptual. De acordo com essa teoria, construir uma metáfora é compreender uma experiência em termos de outra. Essas experiências, por sua vez, organizam-se na forma de domínios. Um deles, o que queremos conceptualizar e tem natureza abstrata, é o domínioalvo; o outro, a partir do qual conceptualizamos o alvo e que tem natureza concreta, é o domínio-fonte. Assim, quando formulamos sentenças do tipo suas afirmações são indefensáveis ou ele atacou cada ponto fraco do meu argumento, isso indica que nós pensamos em uma discussão em termos de guerra, de maneira a criar a metáfora DISCUSSÃO É GUERRA. Nesse caso, DISCUSSÃO é o domínioalvo e GUERRA é o domínio-fonte. Entre esses domínios ocorrem mapeamentos, ou seja, relações estabelecidas entre elementos de ambos os domínios.

Os autores reforçam que não se trata apenas de falar sobre uma experiência em termos de outra, mas de construir todo um sistema conceptual envolvendo essas experiências. Assim, em DISCUSSÃO É GUERRA, mais do que falar sobre discussão como se ela fosse uma guerra, construímos relações de modo a pensar no interlocutor como um oponente; elegemos estratégias de argumentação com vistas à defesa de um ponto de vista e atacamos as falhas do interlocutor; e assim por diante. Essas escolhas não são puramente subjetivas, mas pautadas em uma concepção construída a partir das interações cotidianas com o ambiente em que vivemos, com as pessoas com quem interagimos e com a cultura em que estamos inseridos. Nessa perspectiva, não somos criaturas totalmente autônomas, mas seres existentes como parte de um universo maior, um meio que nos configura e que também é configurado por nós. 
Imbuídos dessas ideias, Lakoff e Johnson (2003) formulam uma alternativa epistemológica, designada pelos autores de "Realismo Experiencialista", que postula a integração entre homem e mundo, corpo e mente, de modo que emoções e abstrações devem ser conceptualizadas a partir de elementos mais concretos, de base corpórea, os quais se construiriam por meio das nossas experiências e emergiriam na língua, na forma, por exemplo, de construções metafóricas reveladoras das nossas visões. Como se vê, nessa perspectiva, a explicação para o fenômeno linguístico da figuratividade adquire novos contornos.

\subsection{A Teoria Neural da Linguagem e 0 conceito de Corporalidade}

Muitas das considerações sobre a base corpórea da linguagem e do pensamento, formuladas pelos cognitivistas da segunda geração a partir da observação das práticas linguísticas cotidianas, encontram respaldo empírico em relatos de experimentos divulgados por pesquisadores da Teoria Neural da Linguagem (doravante, TNL). Esses resultados reforçam o pressuposto de que a cognição é, de fato, situada mental e fisicamente, posto que os fenômenos a ela concernentes não ocorrem em um "limbo" extracorpóreo, mas se concretizam na forma de conexões entre redes neurais. Portanto, a TNL assume o importante papel de ratificar premissas que se mantêm, até hoje, no âmbito dos estudos cognitivos da linguagem.

Por exemplo, os achados obtidos por meio de experimentos realizados principalmente por cientistas das Neurociências, da Psicologia e das Ciências da Computação oferecem argumentos consistentes para os adeptos da TNL na defesa de que, na raiz dos processos de significação - incluindo a construção da figuratividade -, está a simulação de experiências sensoriais e motoras; nesse processo, imaginar, ler ou ouvir relatos acerca de sensações e de ações ativa partes dos mesmos circuitos neurais nelas envolvidos (SOUSA, 2014). A esse respeito, podem ser citados trabalhos sobre o papel da simulação motora na compreensão de sentenças (MASSON; BUB; WARREN, 2008); a simulação e a compreensão atreladas ao uso de verbos (MADDEN; ZWAAN, 2003); a construção de simulações durante a compreensão de sentenças que contêm verbos metaforicamente empregados (GIBBS, 2005); entre outros.

Situar no campo da TNL uma discussão acerca da figuratividade é, sobremaneira, admitir que a construção de sentidos figurativos tem, em sua base, a simulação mental, processo que se constitui como ponto de convergência entre o que se convencionou chamar de literal e o que se considera figurativo. A despeito da separação entre literalidade e figuratividade, hoje se defende, em especial no campo das Ciências Cognitivas, a ideia de que os mesmos mecanismos mentais atuam em ambos os casos. Esse processo de simulação de ações está relacionado à ativação de neurônios-espelho, células que permitem a integração das modalidades visual, auditiva, sensorial e proprioceptiva de maneira que, ao presenciarmos uma ação, ou mesmo lermos ou ouvirmos relatos acerca dela, há ativação desses neurônios de modo semelhante ao que ocorre durante a própria ação. Rizzolatti e Sinigaglia (2008) relatam experimentos cujos resultados comprovam a ativação de neurônios-espelho na área frontal dos cérebros do macaco e do homem.

Conceito imprescindível para nossa compreensão acerca do processo de simulação é o de "esquema de ação" (doravante, esquemas- $X$ ), que podem ser compreendidos como rotinas ou modelos neurais construídos e ativados quando se desempenham ações. De acordo com Arbib (1981), essas estruturas podem ser pensadas como dicionários de ações motoras arquivadas na memória, em que os grupos de neurônios ativados durante a execução de ações equivaleriam às palavras que formam o dicionário. A esse entendimento, com base em Feldman (2006), pode-se acrescentar que esse tipo de esquemas subjaz não só à ação em si, mas também ao seu reconhecimento, planejamento e simulação. Daí compreende-se que a ativação neural, em se tratando de esquemas- $X$, ocorre também 
quando imaginamos uma ação, seja por presenciar outra(s) pessoa(s) executando-a, ou por ler ou ouvir um relato sobre ela.

Se pensarmos em uma ação, por mais simples que pareça, chegaremos à conclusão de que ela é composta por diversas etapas e envolve mais de uma parte do corpo. O ato de pegar uma caneta que está sobre a mesa, por exemplo, exige não só controle sobre a mão (e, evidentemente, sobre os dedos), mas, além disso, depende de algum movimento do braço. Com isso, vários circuitos neurais, com níveis múltiplos de controle, acabam sendo exigidos desde o início da ação até a sua conclusão, passando por várias etapas no decorrer do processo.

$A$ ativação múltipla de circuitos de esquemas- $X$ decorre, também, de fatores relacionados a outros detalhes concernentes ao desempenho de uma ação, como, por exemplo, a força e a velocidade necessárias para que ela seja cumprida a contento. Essas caraterísticas das ações que nós controlamos com vistas a cumprir um determinado objetivo são chamadas de parâmetros, e influenciam diretamente o comportamento dos neurônios envolvidos na ação ou na simulação dela.

Com relação às ações, especificamente, é interessante notar que não se trata da mera ativação de circuitos, mas de modelar um comportamento inteiro, muitas vezes com base em apenas uma pista linguística. Nesse sentido, a noção de aspecto, ou seja, o tempo interno da ação é muito relevante para o entendimento da relação entre esquemas-X e linguagem. Aspecto é o tempo/momento da ação (se já foi concluída, se ainda está em andamento ou se está prevista para acontecer, por exemplo). O aspecto da ação é evidenciado pela pista linguística, a qual ativa um determinado nódulo de timing, como é chamado um subconjunto de neurônios que coordenam a duração dos estados e das ações (que podem ser instantâneos ou se alongar). Assim, nódulos diferentes são ativados dependendo do aspecto da ação que está sendo vivenciado ou relatado. Basta uma palavra para que essa ativação específica ocorra. Desse modo, um verbo conjugado no passado, que indica ação já concluída, ativa circuitos distintos dos que disparam quando o verbo está no gerúndio, tempo que sinaliza ação em andamento. Desse modo, um mesmo esquema pode ensejar combinações, projeções e focalização diferentes, bem como simulações distintas, conforme a situação.

O aparato cognitivo envolvido nos processos de construção de sentidos abrange mais do que os esquemas-X. De fato, a ativação deles ocorre conjuntamente à dos frames, estruturas mentais organizadas a partir das experiências que o homem, guiado por convenções sociais e culturais, vivencia em seu meio. Um conceito de frame compatível com a TNL pode ser utilizado a partir da Semântica de Frames (FILLMORE, 1985), particularmente na fase mais recente desse programa. Nessa perspectiva, o frame é conceituado como uma estrutura cognitiva cujas partes são indexadas por palavras a ela associadas e usadas a serviço do processo de compreensão. Não se trata, portanto, de tomar apenas o léxico por base. Afinal, as palavras não contêm em si o sentido, mas são pistas cuja leitura permite, ao leitor, ativar todo um arcabouço de experiências sociais e culturais vinculadas às palavras por meio dos quais as categorizamos. Nesse sentido, frames podem ser compreendidos, de acordo com Chishman e Bertoldi (2013, p. 36), como "estruturas esquematizadas de conhecimento", frutos da interação não perceptual e não motora com o mundo em que vivemos.

Um exemplo utilizado por Fillmore (1985) é o do frame transação comercial, que inclui elementos como comprador, vendedor, mercadorias e dinheiro, apontados como papéis situacionais, e não como papéis semânticos, tal como previsto pela gramática de casos. Semanticamente associados a esse frame, estão verbos como comprar, vender, pagar, gastar, custar e trocar, cada um deles evocando um aspecto distinto do frame. Assim, o verbo comprar, por exemplo, faz com que fiquem em perspectiva 0 comprador e a mercadoria, deixando o dinheiro usado na transação e o vendedor como elementos de fundo.

Assim, a associação do verbo a um determinado aspecto do frame depende de que se 
conheçam os detalhes que constituem, basicamente, uma transação comercial. Desse modo, a experiência fornece a motivação para as categorias que são representadas pelos itens lexicais, a partir dos quais são ativados, na mente, os frames. Vale salientar, conforme já apontado por Chishman e Bertoldi (2013), que, a depender dos elementos que compõem o texto, enquadram-se algumas propriedades (ou atributos, conceito que será melhor explicitado a seguir) do frame ativado, enquanto outras ficam ao fundo, podendo ser acionadas a qualquer momento.

\subsection{A Metáfora sob o prisma da Teoria Neural da Linguagem}

A perspectiva neural da linguagem se faz presente em Lakoff e Johnson (1999), posto que os domínios da experiência passam a ser compreendidos pelos autores como estruturas cognitivamente situadas e decorrentes de ativações neurais, o que deu à teoria uma abordagem, de fato, corporificada. Além disso, no estudo acerca das metáforas, os autores se debruçam, especificamente, sobre as metáforas primárias e as complexas, dedicando a elas o tratamento apresentado a seguir.

As metáforas primárias caracterizam-se pela coativação neural de domínios de experiências básicas. A metáfora AFETO É CALOR, por exemplo, subjacente a expressões como você está frio comigo, configura-se a partir da ativação concomitante da rede neural relacionada à percepção de afeto e da que está ligada à percepção de calor. Ambas apontam diretamente para uma experiência sensóriomotora básica, vivenciada por nós desde quando, ainda bebês, somos aconchegados no colo de outra pessoa e experienciamos, concomitantemente, o afeto que nos é dedicado e a elevação da temperatura decorrente do contato entre os corpos. Esse processo ocorre sem que tenhamos consciência da sua natureza e do seu desenrolar e, à medida que a coativação neural vai se repetindo, motivada pela vivência recorrente da experiência que a fusão promove, a ligação entre os domínios vai se tornando mais automatizada, a ponto de as expressões metafóricas emergirem na linguagem sem que sequer nos demos conta da presença desse fenômeno nas nossas produções - faladas e/ou escritas cotidianas.

Já as metáforas complexas apontam para um aspecto mais relativizado da cognição humana, pois elas se fundamentam na coativação de frames, estruturas construídas a partir das vivências sociais e culturais que não têm caráter universal, pois culturas e sociedades distintas têm suas particularidades. Pensemos, por exemplo, nas sentenças preciso ganhar tempo; estou perdendo tempo com você; cada minuto será precioso para nós, entre outras. Fazemos essas analogias porque vivemos em uma cultura na qual o trabalho é associado ao tempo que ele toma, e costumamos quantificar esse tempo em horas, semanas ou dias a serem pagos em troca do serviço prestado. Com base nessas práticas típicas nas sociedades industrializadas, pensamos no tempo como um recurso limitado que usamos para cumprir nossas metas e como uma mercadoria valiosa que pode ser usada, gasta, bem ou mal investida, entre outras aplicações comuns ao domínio dinheiro. Assim se estrutura a metáfora TEMPO É DINHEIRO, na qual há dois conceitos distintos que não evocam uma experiência primária, mas sim dois frames diferentes que, por sua vez, são mapeados concomitantemente de maneira a formar uma metáfora característica das sociedades industrializadas e capitalistas.

Lakoff e Johnson (1999) defendem, ainda, que a construção das estruturas cognitivas está subordinada a três níveis de corporalidade que interagem entre si. Um deles é a corporalidade neural, caracterizada pela ação dos agrupamentos de neurônios que, uma vez ativados, permitem criar conceitos (por exemplo, conceptualizar uma flor como vermelha e não como azul, graças aos circuitos neurais que se conectam aos cones - células localizadas em nossos olhos). Há também o nível da corporalidade fenomenológica, que emerge na maneira como esquematizamos nossos corpos e tudo aquilo com que interagimos no nosso cotidiano (como as noções de "à frente" e "atrás", que não existiriam 
se nossos corpos não fossem do jeito que são). Outro nível é o inconsciente cognitivo, que consiste nas operações mentais que estruturam as experiências das quais temos consciência, incluindo-se entre elas o uso e a compreensão da linguagem. Para tanto, faz uso dos aspectos motores, sensoriais e perceptuais dos nossos corpos, ao mesmo tempo em que os guia. Em suma, o inconsciente cognitivo refere-se a todas as estruturas e operações mentais que atuam abaixo do nível da consciência quando fazemos uso da linguagem, da percepção e do raciocínio.

\section{Voltando à questão da Figuratividade}

O debate sobre figuratividade e literalidade toca de perto as questões que envolvem o conceito de categorização. O que se convencionou chamar de significado literal, conforme a concepção clássica de linguagem e pensamento, corresponde ao significado atribuído a um objeto, indivíduo ou situação a partir da verificação de condições de verdade. Já o que se denomina significado figurativo estaria mais relacionado ao emprego de recursos linguísticos para fins estéticos, de maneira que o sentido atribuído não é o que se depreende a partir da análise objetiva da relação entre o que é dito ou escrito e o que se pretende referenciar. Turner (2005) ilustra essa dicotomia a partir do seguinte exemplo: a sentença $O$ sol é uma estrela útil faz com que se atribuam ao sol duas propriedades: a de ter uma utilidade e a de ser uma estrela. Uma vez checada a veracidade da afirmação de que elas, de fato, caracterizam o sol, 0 pensamento acerca dessa estrela e a sentença originada a partir dele são considerados verdadeiros, e o significado a esta atribuído é tido como literal, posto que representa a percepção do que seria, de fato, o sol. Já a sentença o sol é uma joia corresponderia a um tipo distinto de pensamento e de linguagem, considerado não literal, posto que a verificação das condições que permitem considerar um objeto uma joia levam à conclusão de que o sol não é uma delas. Assim, se o sol é uma joia suscita o achado de algum significado "alternativo", subordinado a condições que não correspondem à relação direta entre palavra e referente categorizado, essa atribuição de sentido seria decorrente de um processo de conexão conceptual diferenciado, "figurativo".

Ocorre que, a atenção dada à frequência com que utilizamos a linguagem figurativa sem estranhamento, bem como às questões concernentes a todo o arcabouço por trás da produção e da compreensão da linguagem figurativa já se constituem como uma contraposição à abordagem clássica acerca do literal e do figurativo. Essa tendência é acompanhada por pesquisadores que se inserem na perspectiva da TNL. Bergen (2005), por exemplo, confronta a abordagem clássica ao defender que os estudos nela baseados levam a um entendimento incorreto acerca da relação entre literal e figurativo. Em síntese, depreende-se, dessa concepção, que as palavras têm um sentido intrínseco a elas, e que basta interpretar cada uma delas conforme esse significado para depreender 0 sentido literal do texto. O figurativo, por sua vez, estaria relacionado às chamadas figuras de linguagem, ou seja, estratégias aplicadas pelo produtor do texto para obter, do leitor ou do ouvinte, uma determinada interpretação, sinalizada linguisticamente de modo a se distinguir do sentido literal. A partir da compreensão de que uma frase de conteúdo literal e outra figurativa suscitam atribuições de sentidos diferentes e provocam, cada uma, reações, sentimentos e sensações distintos, depreende-se, na visão clássica, que os fenômenos em questão não poderiam ter a mesma contrapartida cognitiva. Essa visão é confrontada por Bergen (2005), que compreende serem os vários tipos de linguagem figurativa resultados da ativação de diferentes formas de simulação em relação ao processamento da linguagem literal, embora tanto a linguagem figurativa quanto a literal decorram, igualmente, desta função mental, a simulação. O autor propõe, portanto, considerar que os processamentos das linguagens literal e figurativa envolvem os mesmos mecanismos cognitivos, inclusive para que se possa comparar, diretamente, os aspectos concernentes a ambos, embora alguns 
deles, especialmente no tocante à figuratividade, ainda não tenham sido desvendados.

É importante não perdermos de vista que, considerando-se a interface corpo/mente/cérebro/linguagem, é difícil conceber qualquer tipo de processamento linguístico desvinculado do aparato sensorial, motor e perceptual humano, bem como das vivências sociais e culturais cotidianas. Tais fatores se fazem presentes nos processos de simulação mental, que, por sua vez, se integram às diversas ocasiões em que, envolvidos em atividades concernentes à linguagem, precisamos construir sentidos para as histórias que se nos apresentam. Já compreendemos que a simulação mental é guiada por pistas linguísticas e fundamentada em tudo que vivenciamos como sujeitos dotados de certa configuração física e inseridos em determinado(s) grupo(s) social(is). Nesse sentido, Bergen (2005) chama a atenção para o fato de que é preciso considerar as limitações das experiências prévias na definição do que é ou deixa de ser simulado. $O$ autor questiona: se a produção de sentidos envolve a ativação de estruturas relacionadas a experiências já vivenciadas, como é possível compreender o contrafactual, atribuir significados a situações que não foram previamente experienciadas? Nesse sentido, pode-se inferir de Kosslyn et al. (2001) a ideia de que a criatividade e a imaginação, por meio das quais somos capazes de conceber personagens e cenários que não existem no mundo em que vivemos, são propriedades inerentes à condição humana. A capacidade de construir o que é novo a partir de um repertório já existente remonta à tendência de categorizarmos elementos "estranhos" com base no que faz parte das nossas vidas. Não é à toa que alienígenas, por exemplo, são comumente retratados com algumas características humanas (a condição de ser bípede; a configuração da face). Também é muito comum, em programas de televisão em que se mostra a rotina de espécies animais, "romancear" o ritual do acasalamento, narrando-o como um encontro amoroso entre macho e fêmea apaixonados; descrever o momento do parto ou a perda de um membro do bando com clichês que normalmente se repetem quando falamos do nascimento de um bebê humano ou lamentamos $o$ falecimento de um ente querido; e assim por diante. Algo semelhante ocorre quando, ao criarmos histórias ficcionais com seres e lugares fantásticos, recorremos a elementos com os quais nos deparamos cotidianamente. Não se trata apenas de, com base num repertório constituído culturalmente, reconhecer e aceitar a intenção expressa pelo autor; trata-se, também, da identificação do leitor com certos aspectos da obra.

Todas essas observações acerca da categorização do mundo a partir do que somos e vivemos são pertinentes à compreensão do processo de simulação. Afinal, nossas vivências estão na raiz do que simulamos, inclusive quando nos deparamos com construções figurativas.

A questão é que, independentemente das semelhanças e das distinções entre a simulação feita a partir do literal e a que se constrói com base no figurativo, o que está no centro da discussão, no âmbito da TNL, sobre esses processamentos é a ideia de que os mecanismos que subjazem a ambos são os mesmos. Por mais que variem a organização, a apresentação e natureza das pistas linguísticas, ou o tempo necessário para que se construam sentidos para o texto, as estruturas mentais envolvidas em ambos os processamentos são as mesmas.

\section{Conclusão}

Considerando nosso interesse nos mecanismos cognitivos subjacentes aos processos de construção de sentido, e que essas estruturas mentais são o objeto de estudo de abordagens recentes no contexto dos estudos cognitivos da linguagem, ressaltamos a necessidade de investigar esses aspectos com base no aparato teórico oferecido por esse campo de estudo. Assim, partimos do pressuposto de que os processos de categorização estão atrelados à ativação das estruturas cognitivas moldadas por nossas experiências corpóreas e sociais, na interação com o ambiente em que vivemos, e que, na raiz dessa 
ativação, estão os processos de simulação mental, desencadeados a partir das pistas que remetem ao nosso repertório experiencial. Com base no fato de que as Ciências Cognitivas têm procurado responder questões concernentes às relações entre linguagem, cognição e corporalidade, com foco nos mecanismos mentais, é nesse campo de investigação que visualizamos 0 aparato teórico necessário à investigação das estruturas cognitivas que subjazem aos processos concernentes à construção da figuratividade.

\section{Referências}

ARBIB, Michael. Perceptual structures and distributed motor control. In: BROOKS, Vernon (Ed.). Handbook of Physiology: the nervous system v.2. Bethesda: American Physiological Society, 1981, p.1449-1480.

ARISTÓTELES. A arte poética. [S.I.] Disponível em: $<$ http://www.dominiopublico.gov.br/download/te xto/cv000005.pdf>. Acesso em: 22 de junho de 2014.

BERGEN, Benjamin. Mental simulation in literal and figurative language understanding. In: COULSON, Seana; LEWANDOWSKATOMASZCZYK, Barbara (Eds.). The literal and nonliteral in language and thought. Frankfurt: Peter Lang, 2005, p. 255-280. Disponível em: $<$ www2.hawaii.edu/ bergen/papers/figlitbergen .pdf $>$. Acesso em 24 de maio de 2014.

CHISHMAN, Rove; BERTOLDI, Anderson. A semântica de frames como paradigma para os estudos multilíngues: o caso dos frames self_motion e criminal_process em inglês e português. In: Caderno de estudos linguísticos, jan./jun. 2013, Campinas, p. 35-49.

FELDMAN, Jerome. From molecule to metaphor: a neural theory of language. Cambridge: The MIT Press, 2006.

FILLMORE, Charles. Frames and the semantics of understanding. In: Quaderni di Semantica 6.2, 1985, p. 222-254.

GIBBS, Raymond. The poetics of mind: figurative thought, language, and understanding. New York: Cambridge University, 1994.

Embodiment and cognitive science. New York: Cambridge University, 2005.

KENEDY, Eduardo. Gerativismo. In: MARTELOTTA, Mário Eduardo (org). In: Manual de Linguística. São Paulo: Contexto, 2008.
KOSSLYN, Stephen; GANIS, Giorgio; THOMPSON, William. Neural Foundations of Imagery. In: Nature Reviews Neuroscience, n. 2, 2001, p. 635-642.

LAKOFF, George; JOHNSON, Mark. Metaphors we live by. Chicago: The University of Chicago Press, [1980] 2003.

Philosophy in the flesh: the embodied mind and its challenge to western thought. New York: Basic Books, 1999.

MADDEN, Carol; ZWAAN, Rolf. How does verb aspect constrain event representations? In: Memory \& Cognition. 2003, n. 31, p. 663-672.

MASSON, Michael; BUB, Daniel; WARREN, Christopher. Kicking calculators: Contribution of embodied representations to sentence comprehension. In: Journal of Memory and Language, 2008, n.59, p. 256-265.

RIZZOLATTI, Giacomo; SINIGAGLIA, Corrado. Mirrors in the brain: how our mind share actions, emotions and experience. New York: Oxford, 2008.

$\mathrm{ROSCH}$, Eleanor. Principles of categorization. In: ROSCH, E.; LLOYD, B.B. (Eds.). Cognition and categorization. Hillsdale (N.J.): Lawrence Erbium Associates, 1978.

ROSCH, Eleanor; MERVIS, Carolyn. Family resemblances: studies in the internal structure of categories. In: Cognitive Psychology, 7: 573$605,1975$.

SOUSA, Ada Lima Ferreira de. A figuratividade nas histórias em quadrinhos: uma análise das construções metafóricas e metonímicas em $V$ de vingança. 2014. 189 páginas. Tese (Doutorado). Programa de Pós-graduação em Estudos da Linguagem da Universidade Federal do Rio Grande do Norte, Natal, 13 de novembro de 2014.

TURNER, Mark. The literal versus figurative dichotomy. In: COULSON, Seana; LEWANDOWSKA-TOMASZCZYK, Barbara (Eds.). The literal and nonliteral in language and thought. Frankfurt: Peter Lang, 2005, p. 25-52. Disponível em: <http://markturner.org/LitNonlitTurner.pdf >. Acesso em 24 de maio de 2014. 